\title{
Lake characteristics influence how methanogens in littoral sediments respond to terrestrial litter inputs
}

\author{
Kurt M. Yakimovich $\mathbb{1}^{1,2,3} \cdot$ Chloé Orland $^{3}$ - Erik J. S. Emilson $\mathbb{C}^{4} \cdot$ Andrew J. Tanentzap $^{3} \cdot$ Nathan Basiliko $^{1,2}$. \\ Nadia C. S. Mykytczuk ${ }^{1,2,5}$
}

Received: 4 October 2019 / Revised: 5 May 2020 / Accepted: 6 May 2020

(c) The Author(s), under exclusive licence to International Society for Microbial Ecology 2020

\begin{abstract}
Shallow lake sediments harbor methanogen communities that are responsible for large amounts of $\mathrm{CH}_{4}$ flux to the atmosphere. These communities play a major role in degrading in-fluxed terrestrial organic matter (t-OM) - much of which settles in shallow near-shore sediments. Little work has examined how sediment methanogens are affected by the quantity and quality of t-OM, and the physicochemical factors that shape their community. Here, we filled mesocosms with artificial lake sediments amended with different ratios and concentrations of coniferous and deciduous tree litter. We installed them in three boreal lakes near Sudbury, Canada that varied in trophic status and water clarity. We found that higher endogenous nutrient concentrations led to greater $\mathrm{CH}_{4}$ production when sediment solar irradiance was similar, but high irradiance of sediments also led to higher $\mathrm{CH}_{4}$ concentrations regardless of nutrient concentrations, possibly due to photooxidation of tOM. Sediments with t-OM had overall higher $\mathrm{CH}_{4}$ concentrations than controls that had no t-OM, but there were no significant differences in $\mathrm{CH}_{4}$ concentrations with different t-OM compositions or increasing concentrations over $25 \%$. Differences among lakes also explained variation in methanogen community structure, whereas t-OM treatments did not. Therefore, lake characteristics are important modulators of methanogen communities fueled by t-OM.
\end{abstract}

\section{Introduction}

Methanogenic archaea in freshwater sediments produce $\mathrm{CH}_{4}$ as one of the main terminal anaerobic steps of organic matter (OM) decomposition. Consequently, freshwaters are estimated to contribute $103 \mathrm{Tg}$ of $\mathrm{CH}_{4}$ to the atmosphere annually [1], where it has a greenhouse gas effect 34-times more potent than $\mathrm{CO}_{2}$ over a 100 year period [2]. Over the

Kurt M. Yakimovich

kurtyakimovich@gmail.com

1 Vale Living with Lakes Centre, Laurentian University, Sudbury, ON, Canada

2 Department of Biology, Laurentian University, Sudbury, ON, Canada

3 Ecosystems and Global Change group, Department of Plant Sciences, University of Cambridge, Cambridge, UK

4 Natural Resources Canada, Great Lakes Forestry Centre, Sault Ste. Marie, ON, Canada

5 School of the Environment, Laurentian University, Sudbury, ON, Canada last decade, the estimates of global lake contribution to atmospheric $\mathrm{C}$ have increased due to new data on lake sizes, distributions and outgassing measurements [3]. Both natural and anthropogenic wave action, ebullition, and plantmediated diffusion can reduce residence times of $\mathrm{CH}_{4}$ in the sediments and water column, or create a shortcut bypassing aerobic planktonic $\mathrm{CH}_{4}$ oxidizing bacteria [4, 5]. All of these processes enhancing $\mathrm{CH}_{4}$ evasion to the atmosphere are common to shallow areas of freshwater systems. Even ebullition, which occurs homogenously across profundal lake basins [6], was found by West et al. [7] to occur at significantly higher rates in waters $<6 \mathrm{~m}$ in depth.

A large source of $\mathrm{OM}$ for methanogens in shallow sediments comes from terrestrial plants and soils, with an estimated $5.1 \mathrm{Pg}$ of $\mathrm{C}$ per year entering aquatic systems from land [3]. On a local level, terrestrial catchments can contribute greatly to the $\mathrm{OM}$ content of littoral zones of lakes, either through direct litterfall inputs or as partially decomposed OM leaching from soils and/or transported in streams $[3,8]$. Once in a lake, terrestrial organic matter (t$\mathrm{OM}$ ) is further processed by bacteria and fungi, being incorporated into microbial biomass and metabolites that 
can then be transferred to higher trophic levels, mineralized or buried in sediments [9-11]. In surface layers of sediments (where most methanogenesis occurs [12]), methanogens utilize $\mathrm{H}_{2}$ and/or small C-molecules resulting from the $\mathrm{OM}$ decomposition in redox reactions leading to the production of $\mathrm{CH}_{4}$ [9]. Land use changes and climate driven shifts in vegetation are altering the amounts and composition of plant litter that flows into lake ecosystems [13, 14].

While we do not fully understand the effects that t-OM inputs have on sediment communities, we do know that different plant species affect the fermentative bacterial decomposer community and methanogenesis rates in different ways [15]. Recently, we found that lake sediments amended with $\mathrm{OM}$ dominated by tree foliage resulted in 400-times less $\mathrm{CH}_{4}$ being produced than when amended with cattails in a lab setting [16]. There were even differences between tree leaf litter types, with higher methanogenesis found in coniferous litter amended sediments versus deciduous-likely due to the increase of inhibitory polyphenolics that leached from the latter. The different OM sources also supported different bacterial and fungal communities in the lab [15]. Most strikingly, the methanogen community was inhibited in sediments dominated with tree leaf litter (whether coniferous or deciduous)—despite having similar taxonomic composition to sediments with OM dominated by an emergent macrophyte [15]. Therefore, these results suggested that the composition of OM reaching lake sediments can have a large effect on methanogen communities and their rates of methanogenesis.

Lab conditions can limit generality by ignoring potentially important physicochemical factors present in situ. For example, flask incubations in strictly dark conditions would ignore any effects that photoexposure can have by oxidizing high molecular weight $\mathrm{C}$ (HMW-C; humified plant $\mathrm{OM}$ ) $[17,18]$, which often contains known inhibitors of methanogenesis [19, 20]. Water clarity is thus a potentially important factor influencing t-OM decomposition, and its subsequent complexity (e.g. aromaticity and size fractions). Bacterial decomposers are also affected by HMW-C and are important to consider as they are syntrophic partners of methanogens, supplying them with requisite metabolites. Clearer overlying water has been shown to result in higher $\mathrm{CO}_{2}$ production in sediments due to the utilization of more labile photo-degraded HMW-C by bacteria [21]. However, bacteria in lakes with darker waters invest more in the production of energetically costly enzymes that can degrade aromatic compounds, resulting in lower rates of t-OM mineralization [21].

Here, we hypothesize that clearer overlying lake water will result in higher sediment methanogenesis due to greater amounts of photooxidation, given the same t-OM input. Further, the clearer lake water may increase heat transfer into the sediments, stimulating microbial activity.
The higher concentrations of $\mathrm{CH}_{4}$ will result from both a greater supply of low molecular weight metabolites and removal of inhibitory $\mathrm{HMW}-\mathrm{C}$ due to photooxidation. We further predicted that deciduous litter will result in more humified dissolved OM (DOM) in the sediments, and subsequently less methanogenesis than in sediments containing more coniferous litter. However, as lakes can also vary in their endogenous nutrient loads, we tested how these predictions varied across lakes with different trophic statuses. To test these predictions in situ, we constructed sediments spanning an OM concentration gradient from deciduous and coniferous litter mixes. These sediments were installed into mesocosms in three different boreal lakes that varied in trophic status-including water clarity -allowing us to assess how the methanogen community and methanogenesis developed with different terrestrial litter inputs under different photoexposure. Further, we also examined the methanogen community composition and phylogenetic diversity to assess if the different experimental and in situ conditions had a filtering effect on community assembly, which could explain variation in methane concentrations.

\section{Methods}

\section{Study lakes}

We studied three lakes in the same region that varied in their trophic states as defined by Williamson et al. [22], using mean $( \pm \mathrm{SE})$ total phosphorous $(\mathrm{TP})$ and colored dissolved organic matter (CDOM; absorption at $320 \mathrm{~nm}$ ) from mid-lake surface grabs taken during our sampling. Swan lake $\left(46^{\circ} 21^{\prime} 59^{\prime \prime} \mathrm{N}, 81^{\circ} 3^{\prime} 49^{\prime \prime} \mathrm{W}\right.$; area: $\left.0.06 \mathrm{~km}^{2}\right)$ was oligotrophic with TP concentrations of $9.3 \pm 0.4 \mu \mathrm{g} \mathrm{L}^{-1}$ and CDOM of $1.5 \mathrm{~m}^{-1}$. Lake Laurentian $\left(46^{\circ} 27^{\prime} 30^{\prime \prime} \mathrm{N}, 80^{\circ} 56^{\prime} 0^{\prime}\right.$ $\mathrm{W}$; area: $1.57 \mathrm{~km}^{2}$ ) was mixotrophic with TP levels of 35.3 $\pm 2.5 \mu \mathrm{g} \mathrm{L}^{-1}$ and CDOM of $26 \mathrm{~m}^{-1}$. Ramsey Lake $\left(46^{\circ} 28^{\prime}\right.$

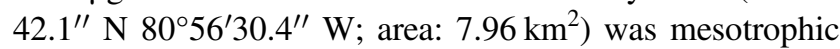
with TP levels of $8.2 \pm 0.5 \mu \mathrm{g} \mathrm{L}^{-1}$ and a CDOM value of $9.2 \mathrm{~m}^{-1}$. Both Swan and Laurentian were surrounded by low-density mixed deciduous and coniferous forests, with catchments that contain granite outcroppings (10-20\%) and sedge- and shrub-dominated marshes and peatlands (5-10\% and $20 \%$ for Swan and Laurentian, respectively). Lake Ramsey was similarly surrounded by coniferous and deciduous forest, but with $21-25 \%$ of its shorelines developed with urban parks and permanent residences (https://www.greatersudbury.ca/play/beaches-and-lakes/la kes/local-lake-descriptions/ramsey-lake/). Lakes are hereafter referred to by their trophic status, except Lake Laurentian will be referred to as dystrophic, to avoid confusion with the common use of mixotrophic as a feeding strategy. 


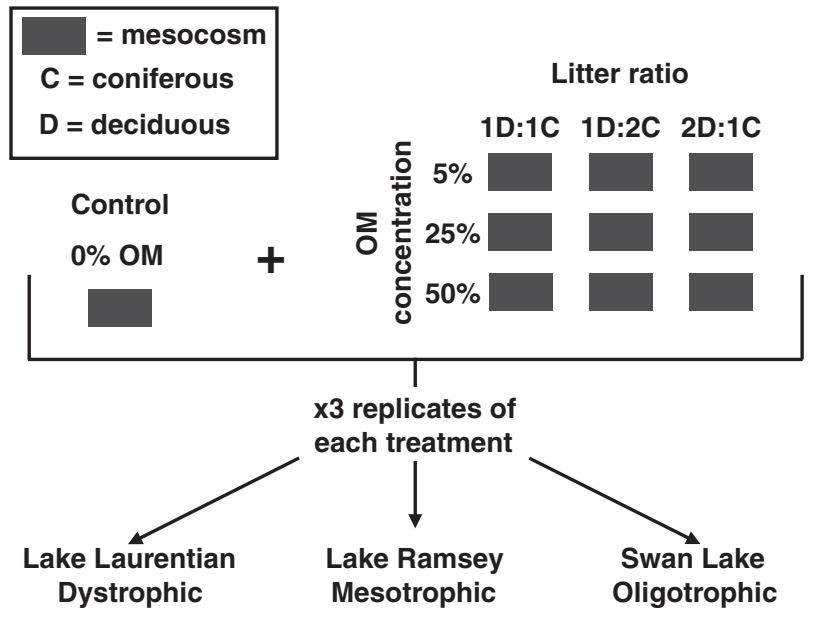

Fig. 1 A schematic of the experimental treatments for this study. Each lake had a total of nine experimental treatments, and one control treatment that were triplicated. In total each lake had 30 mesocosms that were installed for this study.

\section{Experimental design-mesocosm construction}

Mesocosms containing artificially constructed sediments were installed by submerging them during July 2015 into the littoral zones of all three lakes $(0.3-0.75 \mathrm{~m}$ water depth), as described by Tanentzap et al. [23]. Here we briefly describe the experimental design and depict it in Fig. 1. The sediments used in this study were constructed as a mix of inorganic material and an OM concentration gradient across three different ratios of coniferous to deciduous leaf litter: $1: 1,1: 2$, and $2: 1$ at $0,5,25$ and $50 \%$ OM concentration on a dry weight basis. The inorganic and organic matter were both sourced locally, and were mixed at a particle size that simulated vertical structuring in local lake sediments [23]. The deciduous leaf litter consisted primarily of Acer rubrum, Betula papyrifera, Populus tremuloides, and Quercus spp., and the coniferous of Pinus spp. The sediments were placed in $17.5 \mathrm{~L}$ HDPE bins that were $50.8 \times$ $38.1 \times 12.7 \mathrm{~cm}$ to a total height of $8 \mathrm{~cm}$ of sediment, and each treatment was installed in triplicate in each lake. In total, there were 27 mesocosms with t-OM treatments and 3 control mesocosms with inorganic material only per lake. Each mesocosm was fitted with a pore-water sampler made from a $3 \mathrm{~mL}$ polypropylene syringe that had a slit cut into the bottom, was wrapped in $1 \times 1 \mathrm{~mm}$ mesh to filter large particles out of water during sampling, and inserted horizontally $1 \mathrm{~cm}$ below the sediment surface on one side of the mesocosm. A nylon tube was fitted to the tip of the syringe extending up to a float on the surface of the water to allow for continuous undisturbed sampling of pore water from floating platforms (see Tanentzap et al. [23]). The mesocosm installations in each lake were equipped with 12 HOBO temperature and light meters and data loggers set to take hourly readings (Onset Computer Corporation, Bourne,
MA, USA). The bins were covered in $1 \times 1 \mathrm{~mm}$ nylon mesh to keep OM contained within the mesocosm as it saturated, and started to decompose, and increased in density. The mesh also protected the OM from being washed out of the mesocosms during storms and other times of intense wave action, but still allowed light to reach the sediment surface. As demonstrated in Tanentzap et al. [23], this experimental design allowed for comparable conditions to adjacent naturally occurring lake sediments, allowing for realistic inference of how sediment methanogens would respond to our treatments.

\section{Pore water measurements}

Pore water from each mesocosm was sampled monthly after installation from August through October 2015. Samples were taken roughly 30 days apart weather permitting for each lake, with lakes being sampled in consecutive days in the same order every month-Ramsey, Swan then Laurentian. Pore water was used to assess sediment conditions during decomposition, by recording temperature, $\mathrm{pH}$, dissolved $\mathrm{CO}_{2}$ and $\mathrm{CH}_{4}, \mathrm{DOC}$, and optical properties of the dissolved organic matter (DOM). During field sampling, $\mathrm{pH}$ and temperature were measured immediately with a handheld thermometer and pH meter (HI 9126, Hanna Instruments, Woonsocket, RI, USA). Pore water samples were then filtered through $0.5 \mu \mathrm{m}$ pore size silica filters into 25 $\mathrm{mL}$ glass vials and acidified with $125 \mu \mathrm{L}$ of $4 \mathrm{M} \mathrm{HCl}$ for later analysis of DOC and DOM. DOM optical properties were assessed via fluorescence EEMs (excitation-emissions matrices) measured on an Agilent Cary Eclipse fluorescence spectrophotometer in ratio $(\mathrm{S} / \mathrm{R})$ mode with a $1-\mathrm{cm}$ pathlength cuvette. EEMs were created by excitation and emission intensities (EX: $250-450 \mathrm{~nm}$ in $5 \mathrm{~nm}$ steps, EM: $300-600 \mathrm{~nm}$ in $2 \mathrm{~nm}$ steps) corrected for inner-filter effects using absorbance measured with an Agilent Cary 60 UVVIS (Agilent Technologies Santa Clara, California, USA). DOC was measured using a Shimadzu TOC-5000A in nonpurgeable organic carbon mode (Shimadzu Corp, Kyoto Japan). The mHIX humification index was calculated using the resulting pore water data (mHIX; modified by Ohno [24],), with higher values (closer to 1) indicating greater amounts of humified DOM present.

For analysis of $\mathrm{CH}_{4}$ and $\mathrm{CO}_{2}$ a $60 \mathrm{~mL}$ syringe was filled to $43 \mathrm{~mL}$ with pore water and acidified with $2 \mathrm{~mL}$ of $0.5 \mathrm{M}$ $\mathrm{HCl}$ in the field. $15 \mathrm{~mL}$ of atmospheric air was pulled in, the syringe was shaken for $2 \mathrm{~min}$, and then left to sit for $30 \mathrm{~s}$ to equilibrate. $10 \mathrm{~mL}$ of the headspace was drawn into a separate syringe and analyzed on a SRI 8610C-0040 greenhouse gas model gas chromatograph (SRI Instruments, Torrance, CA, USA) fitted with a $0.5 \mathrm{~mL}$ sample loop and a column temperature of $105^{\circ} \mathrm{C}$. Gases were detected with a flame ionization detector for $\mathrm{CH}_{4}$ and an 
inline methanizer to detect $\mathrm{CO}_{2}$ after reduction to $\mathrm{CH}_{4} \cdot \mathrm{CH}_{4}$ measurements were performed within $24 \mathrm{~h}$ of field sampling and final pore water concentrations were calculated using the methods of Aberg and Wallin [25] by subtracting ambient air additions, applying the Bunsen solubility coefficient and ideal gas law while accounting for $\mathrm{pH}$ and water temperature. The $\mathrm{CH}_{4}$ values were analyzed as point measurements taken on each sampling date, and are a net balance of methanogenesis and any methanotrophy that occurred within the mesocosms.

\section{Methanogen community sampling}

To analyze methanogen communities, we collected surface sediments ( $\sim$ top $5 \mathrm{~cm}$ ) with a scoop (sterilized using $70 \%$ ethanol) through an $8 \mathrm{~cm}$ slit in the mesh covering the mesocosms monthly from August to October 2015. The scoop was filled such that excess lake water was excluded as sediments were deposited into individual sterile Whirl$\mathrm{Pak}^{\circledR}$ sample bags. Samples were frozen at $-20^{\circ} \mathrm{C}$ within a few hours after collection until being freeze-dried at $-40{ }^{\circ} \mathrm{C}$ for storage to keep the microbial community static from the time of sampling [26]. DNA was extracted from the lyophilized sediments in duplicate for each sample then pooled using the MoBio PowerSoil kit (MoBio, Carlsbad, CA, USA). Samples were then amplified using $2 \mu \mathrm{L}$ of the forward and reverse primers: mlasF (5'-GGT GGT GTM GGD TTC ACM CAR TA- $3^{\prime}$ ) and mcrA-rev ( $5^{\prime}$-CGT TCA TBG CGT AGT TVG GRT AGT-3') to target the methanogenesis gene methyl coenzyme-M reductase ( $m c r \mathrm{~A})$ [27]. Amplification was performed using $10 \mu \mathrm{L}$ of Qiagen Multiplex PCR Master Mix (Qiagen, Valencia, CA, USA), $4 \mu \mathrm{L}$ of sterile double-distilled water and $2 \mu \mathrm{L}(10 \mathrm{ng} / \mu \mathrm{L})$ of DNA extract in a total volume of $20 \mu \mathrm{L}$, with the following cycling conditions: initial denaturation of $15 \mathrm{~min}$ at $95^{\circ} \mathrm{C}$, 35 cycles at $94{ }^{\circ} \mathrm{C}$ for $30 \mathrm{~s}, 55^{\circ} \mathrm{C}$ for $45 \mathrm{~s}, 72{ }^{\circ} \mathrm{C}$ for $30 \mathrm{~s}$, and final elongation of $10 \mathrm{~min}$ at $72{ }^{\circ} \mathrm{C}$. Sequencing libraries were prepared using a dual indexing strategy with unique 6-bases indexes synthesized using the Trugrade process (IDT, Leuven, Belgium) added to the primers to allow multiplexing of pooled libraries. These index primers were added through a second amplification step, using reactions containing $2 \mu \mathrm{L}$ of both the forward and reverse indexing primers (i5and i7 respectively, $1 \mu \mathrm{M}$ each) and 10 $\mu \mathrm{L}$ of Qiagen Multiplex PCR Master Mix (Qiagen), and 8 $\mu \mathrm{L}$ of template DNA, totaling a $22 \mu \mathrm{L}$ reaction volume. The following reaction conditions were used: initial denaturation of $15 \mathrm{~min}$ at $95^{\circ} \mathrm{C}, 10$ cycles at $98^{\circ} \mathrm{C}$ for $10 \mathrm{~s}, 65^{\circ} \mathrm{C}$ for 30 $\mathrm{s}, 72{ }^{\circ} \mathrm{C}$ for $30 \mathrm{~s}$, and final elongation of $5 \mathrm{~min}$ at $72{ }^{\circ} \mathrm{C}$. Resulting amplicons were quantified on a FLUOstar OPTIMA plate reader at $545 \mathrm{~nm}$ (BMG Labtech, Aylesbury, UK) and pooled in groups of eight in equimolar quantities $(150 \mathrm{ng})$. Final libraries were purified using an
Agencourt AMPure XP beads kit (Beckman Coulter Genomics, Indianapolis, IN, USA). Amplicons were quantified on a Quantstudio 12k Flex Real-Time PCR system (Applied Biosystems, Warrington, UK) with $6 \mu \mathrm{L}$ of KAPA SYBR FAST mix and primers (KAPA Biosystems, Wilmington, MA, USA) and $2 \mu \mathrm{L}$ water, with the following reaction conditions: $95^{\circ} \mathrm{C}$ for $5 \mathrm{~min}, 35$ cycles at $95^{\circ} \mathrm{C}$ for $30 \mathrm{~s}$ and $60^{\circ} \mathrm{C}$ for $45 \mathrm{~s}$. Amplicon size was checked via an Agilent 4200 TapeStation (Agilent Technologies) and pooled into a single sample in equimolar concentrations. The final library concentration was determined with a Quant-it PicoGreen dsDNA Assay kit (Invitrogen, Eugene, OR, USA). Paired-end amplicon sequencing was then carried out on an Illumina MiSeq platform (500 cycles, $2 \times$ $250 \mathrm{bp}$, paired-end) using the V2 reagent kit (Illumina, San Diego, USA). All raw fastq files were uploaded to the European Nucleotide Archive under project accession PRJEB34337.

Reads were analyzed using PandaSeq [28]. Forward and reverse reads were merged, quality filtered by discarding singletons and chimeras in USEARCH v8.1.1861 [29], and taxonomy was assigned in QIIME I using the Ribosomal Database Project (RDP) classifier with default settings (a naïve Baysian classifier; Wang et al. [30]), and the mcrA database created by Yang et al. [31].

\section{Phylogenetic analysis}

To complement the taxonomy assignments from the RDP classifier and assess phylogenetic diversity, sequences from this study and our previous work with lab-incubated plant litter amended lake sediments were used to construct a phylogenetic tree (Yakimovich et al. [15]). Our mcrA sequences along with representative methanogen sequences from GenBank [32], were aligned using MAFFT [33]. Alignments were manually edited using MEGA [34]. Maximum-likelihood phylogenetic trees were then constructed with 1000 bootstrap replicates using IQ-TREE [35].

\section{Statistical analysis}

All analyses were performed in R v3.3.2 (R Core Team [36]), and data was imported using the phyloseq package [37]. The first question we asked was the influence of our experimental parameters on $\mathrm{CH}_{4}$ concentrations, which were analyzed as point measurements for each sampling month-August-October. Thus, a mixed effect models were fitted to predict $\mathrm{CH}_{4}$ concentration given lake identity, litter ratio, litter concentration, and sampling month. Each mesocosm was repeatedly resampled and was set as a random effect in all mixed-effect models. All explanatory variables were treated as factors, and models were fitted 
using the nlme package in $\mathrm{R}$ [38]. A post-hoc Tukey's pairwise comparison of treatments was performed using the emmeans package in $\mathrm{R}$ to calculate the estimated marginal means [39].

To look at the inhibitory effect of HMW-C on methanogenesis, a mixed-effect model was fitted predicting $\mathrm{CH}_{4}$ concentrations given the interaction and main effects of mHIX and lake, while also considering sampling month and litter ratio. The differences in slope were compared using the emmeans package and were plotted with the interactions package [40].

To examine the effects of experimental treatments on methanogen community structure, we used a permutational multivariate analysis of variance (PERMANOVA) using the $\mathrm{R}$ vegan package [41]. To visualize changes in the methanogen communities, a non-metric multi-dimensional scaling analysis was estimated in vegan using a Bray-Curtis dissimilarity matrix [41]. To determine if any methanogens were specifically associated with any lake or litter ratio (and therefore t-OM type), indicator species analysis was performed using the indicspecies package in $\mathrm{R}$ via a multi-level pattern analysis [42]. OTU richness was also assessed in each sample using the Chao 1 index, and was calculated using the fossil package in R [43].

\section{Results}

\section{How did the litter ratio and concentration affect methanogenesis over time?}

Net $\mathrm{CH}_{4}$ concentrations in the pore water were significantly higher in all mesocosms that received leaf litter compared with the controls as revealed by the mixed effect model with post-hoc pairwise comparisons (Fig. 2a; $p<0.0001$ for all comparisons). Although, mesocosms with more coniferous litter than deciduous (1D:2C) had higher $\mathrm{CH}_{4}$ concentrations on average, there were no significant differences between the mesocosms with different litter ratios in any of the lakes ( $p>0.4$ for all pairwise comparisons). However, within each ratio treatment, increasing litter concentration from $0 \%$ (controls) to 5 and $25 \%$ increased $\mathrm{CH}_{4}$ production, but increasing litter concentration to $50 \%$ led to a significant drop in methanogenesis (Fig. 2b). We observed fluctuations of $\mathrm{CH}_{4}$ concentrations over time indicating that the mesocosms were likely in a steady state. $\mathrm{CH}_{4}$ was diffusing out as would be seen in real sediments, and not simply accumulating (Fig. 2c).

The only temperature effect on $\mathrm{CH}_{4}$ concentration we found was a uniform change with seasons across all lakes. The small differences in temperature between lakes was unable to explain the differences in $\mathrm{CH}_{4}$ levels in mixed effect models, and were not significantly different (Mixed
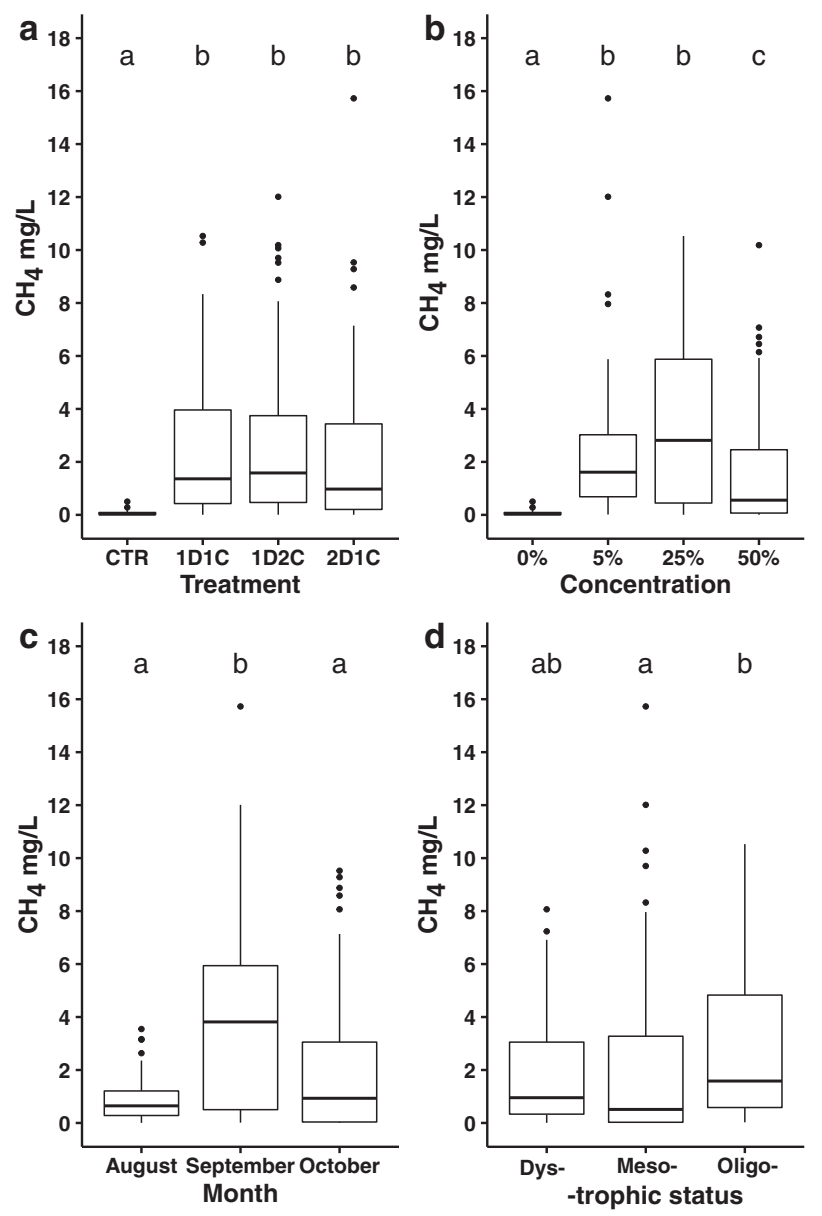

Fig. $2 \mathrm{CH}_{4}$ concentrations accross experimental treatments. Subplots are seperated by a litter ratio, b litter concentration, $\mathbf{c}$ sampling month, and $\mathbf{d}$ lake, with controls included in the averages for sampling month and lake. The litter treatments have the ratios abbreviated with $\mathrm{C}$ meaning coniferous and D meaning deciduous, and the number representing the respective ratio value. Lowercase letters above each boxplot indicates groups of statistically similar averages from post-hoc pairwise comparisons with the mixed effects models that included mesocosm as a random effect.

effect model; $p>0.05)$. $\mathrm{CH}_{4}$ concentration in the month of August shortly after mesocosms were installed in the lakes was relatively low, and then increased by 4.6-times over September across all treatment types and lakes excluding controls (Fig. 2c). As the season changed between September and October, the average water temperature around the mesocosms decreased $\left(20.2{ }^{\circ} \mathrm{C} \mathrm{SE} \pm 0.01\right.$ to $10.1{ }^{\circ} \mathrm{C} \mathrm{SE}$ $\pm 0.01)$ in all lakes, which corresponded with an average 0.5-times decrease in methanogenesis (Fig. 2c).

\section{Did the lakes differ in methane concentrations?}

The three lakes had different concentrations of $\mathrm{CH}_{4}$ within the mesocosms. The dystrophic lake had the lowest $\mathrm{CH}_{4}$ concentrations on average $(1.86 \mathrm{mg} / \mathrm{L} \mathrm{SE} \pm 0.22)$, with the mesotrophic having the second lowest $(2.09 \mathrm{mg} / \mathrm{L} \mathrm{SE} \pm$ 


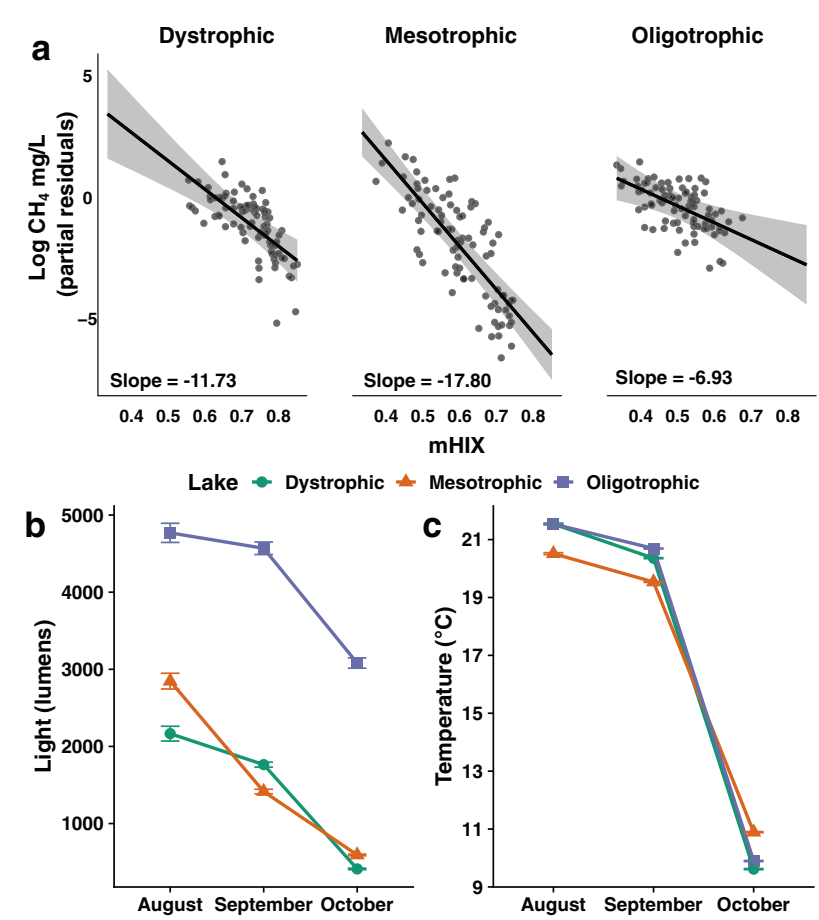

Fig. 3 Differences in lake characteristics corresponded with differences in $\mathbf{C H}_{4}$ concentrations. a The plotted slopes for the effect of mHIX on $\mathrm{CH}_{4}$ concentrations for each from a mixed-effect model, polygons are $95 \%$ confidence intervals. b Average light levels and c) temperature from sensors placed on the top of 12 mesocosms in each lake over each sampling month. Error bars are standard errors.

$0.33)$, and the highest was in the oligotrophic lake $(2.92 \mathrm{mg} /$ $\mathrm{L} \mathrm{SE} \pm 0.32$; Fig. $2 \mathrm{~d}$ ). We then tested our hypothesis that different levels of HMW-C could be driving these observed differences in $\mathrm{CH}_{4}$ production, using measured DOM humification levels in porewater (mHIX index). While litter concentration had little effect on mHIX in a mixed-effect model, a litter ratio of more coniferous material had lower mHIX values than all the other treatments in all lakes $(p<$ 0.001 for all comparisons). On average, the humified DOM levels were different between all lakes, with decreasing values observed in the dystrophic, mesotrophic, and finally the oligotrophic lake (all comparisons $p<0.0001$ ). For this reason, we let the hypothesized inhibitory effects of mHIX vary between lakes in a mixed-effect model as an interaction term. Overall mHIX was negatively associated with $\mathrm{CH}_{4}$, but the inhibitory effect of mHIX (the slope for each lake from the model) was different in each lake (Fig. 3a). On average the effect of mHIX on $\mathrm{CH}_{4}$ concentrations (taken from the model estimates) was over 1.6 and 2.6times less in the oligotrophic lake than in the dystrophic and mesotrophic lakes respectively (Fig. 3a).

Physicochemical differences between the lakes included differing light irradiance of the sediments and $\mathrm{pH}$ of the pore water. The mesocosms in the oligotrophic lake were consistently exposed to higher amounts of light, receiving
2.2- to 7.5-times more light than the other two lakes (Fig. 3b), which received similar levels. Differing light levels did not affect water temperature however, and temperatures varied littles across all lakes, at least at the depth of the mesocosm installations. (Fig. 3c). A mixed effect model looking at the effect of the treatment factors on $\mathrm{pH}$ showed the controls (all inorganic matter) had higher $\mathrm{pH}$ values on average ( $p<0.001$ for all comparisons), but there were no differences between the mesocosms with leaf litter ( $p>0.09$ for all comparisons). The same mixed effect model showed that on average the $\mathrm{pH}$ increased over time in all mesocosms in all lakes (by 0.5 between August and September, and 0.6 between September and October), and the oligotrophic lake had the lowest values on average $(\mathrm{pH}$ 5.7), followed by the dystrophic lake ( $\mathrm{pH}$ 6.3) and the mesotrophic lake (pH 6.4).

\section{Does the methanogen community vary among lakes and leaf litter treatments over time?}

The community was defined by a total of 31 methanotrophic OTUs across all samples, with no known methanotrophs detected. The community composition subsequently varied among all lake (PERMANOVA: $F_{2,251}=60.71, R^{2}=0.28$, $p=0.001$ ), litter concentrations (PERMANOVA $F_{2,251}=$ 20.94, $R^{2}=0.10 p=0.001$ ), and sampling month (PERMANOVA $\left.F_{1,251}=17.65, R^{2}=0.04, p=0.001\right)$, but not among litter type ratio (PERMANOVA $F_{3,251}=1.29, R^{2}=$ $0.001, p=0.259$ ). To visualize this variation, an NMDS ordination was fitted in three dimensions to maintain stress values below 0.2. This NMDS revealed the differences between the methanogen communities in each lake along axes 1 and 2 (Fig. 4). By contrast, axes 2 and 3 showed that the variation in communities caused by different concentration of $\mathrm{OM}$ was likely driven by the much larger variation in the composition of methanogens in the controls versus all other treatments (Fig. 4).

All methanogen OTUs were assigned to one of five Orders via phylogenetic analysis (Fig. 5). Thirteen OTUs were assigned to Methanobacteriales, six to Methanomicrobiales, five to Methanosarcianles, four to Methanomassiliicoccales, and three to Methanocellales. Temporally, the taxonomic richness increased in all mesocosms from August to September, with an increase in the Chao 1 richness index of 1.41-1.65 times across all lakes, which then plateaued into October (Fig. 6a). Indicator analysis showed that OTU 9 (Methanomassiliicoccales) was significantly associated with mesocosms containing leaf litter amendments, and increased in abundance in all lakes over time (Multi-level pattern analysis: $p=0.001$; Fig. $6 b$ ).

Despite the increasing species richness, all mesocosms including controls, were dominated by two Methanobacteriales (OTU 1 and 2). Together, these OTUs comprised 


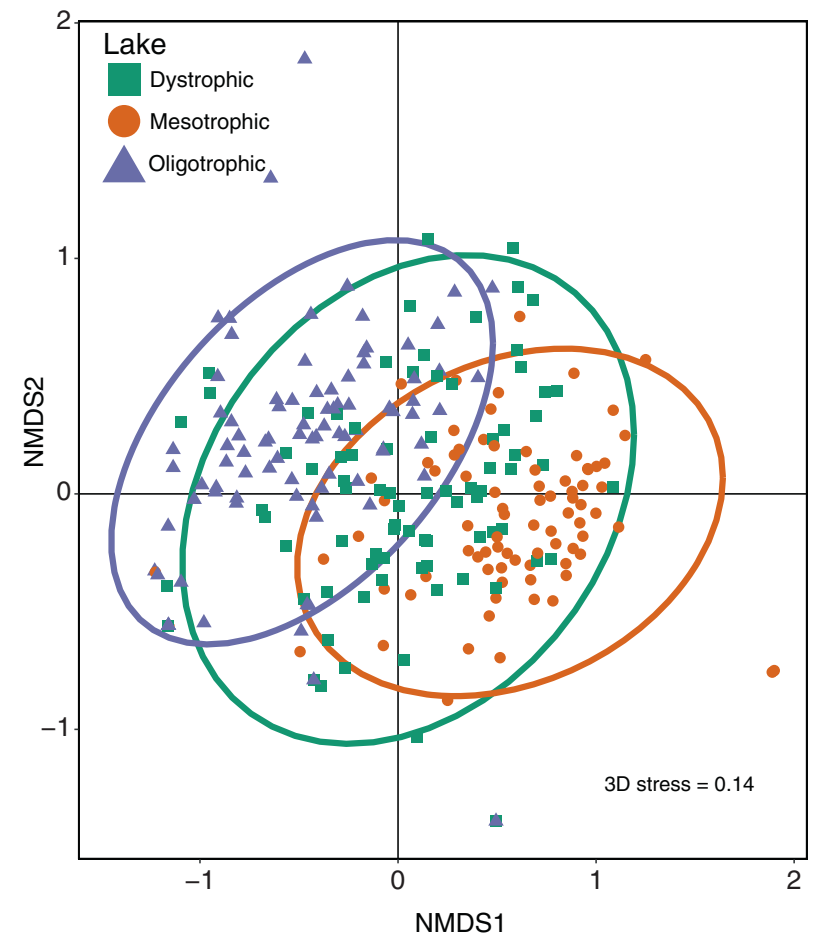

Fig. 4 NMDS of methanogen community composition estimated with a Bray-Curtis dissimilarity matrix. Left panel presents axis 1 and 2, with lake highlighted, and the right panel shows axis 2 and 3

$>90 \%$ of the relative abundance in any sample. However, abundances of these two OTUs changed over time differently in each lake. OTU 2 increased in relative abundance over time in both the dys- and mesotrophic lakes as OTU 1 decreased over time, whereas OTU 1 remained dominant in the oligotrophic lake over time (Fig. 7).

\section{Discussion}

Our goal was to assess the effects that different terrestrial tree litters can have on the mineralization rates and composition of littoral sediment methanogens in lakes with different trophic statuses. We demonstrate that the addition of litter to sediments with different trophic statuses increases $\mathrm{CH}_{4}$ concentration and methanogen diversity in sediments. However, the type of tree litter inputs had no distinct effect on $\mathrm{CH}_{4}$ concentration or on methanogen community structure, which indicates that changes in forest composition around boreal lakes may not have immediate impacts on methanogenesis. Consequently, these results suggest that lake $\mathrm{CH}_{4}$ budgets can be forecasted based on future forest productivity rates, without needing much knowledge on forest composition.

We observed that increasing OM concentrations resulted in increased $\mathrm{CH}_{4}$ concentrations to a certain threshold, in this case $50 \%$ (Fig. 2b; [15]). To our knowledge, no

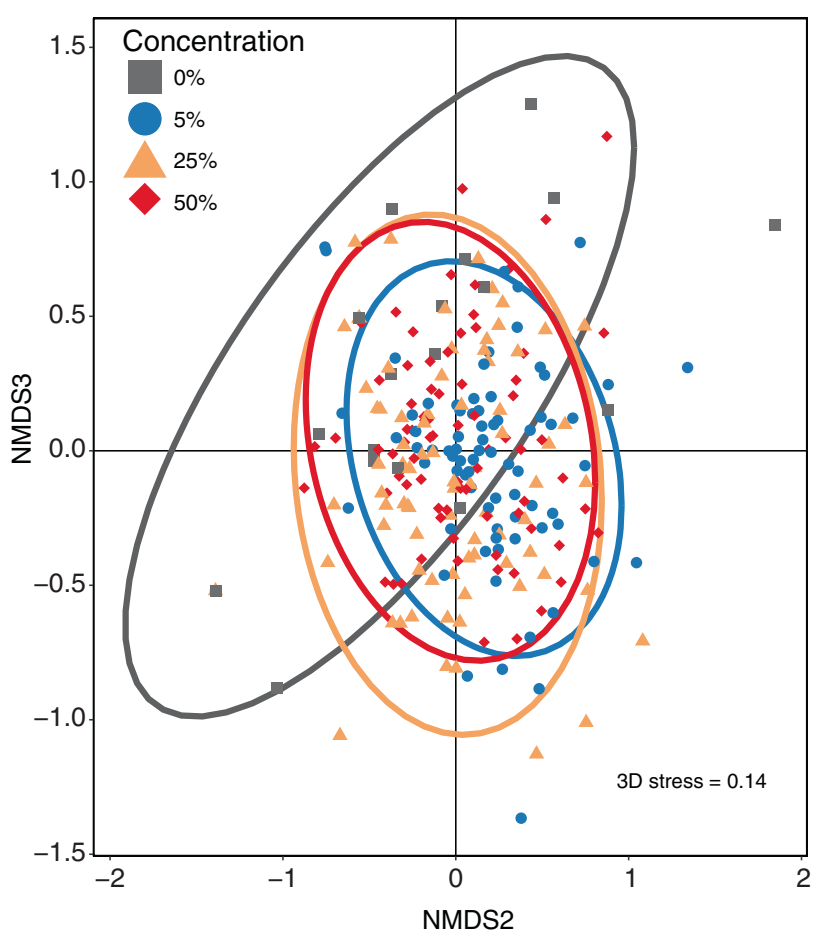

with OM concentration highlighted. The stress value is printed in the lower right-hand corner of each plot, and $95 \%$ confidence ellipses are drawn around the groups.

research exists that directly examines how thresholdquantities of $\mathrm{OM}$ can inhibit methanogenesis. We previously hypothesized that lower methanogenesis could be caused by increased competition from other microbes, such as sulfate reducers that are capable of $\mathrm{H}_{2}$ and/or acetate utilization, and whose populations could have increased with the addition of OM [15]. An additional mechanism that could be explored is the effect of the accumulation of humic acids and polyphenols that exude from leaf litters immersed in water [16]. These compounds could inhibit the biochemical activity of litter decomposition by the syntrophic microbial partners of methanogens (e.g., inhibition of extracellular enzymes). Understanding these dynamics could help constrain the factors that modulate methanogenesis with influxes of t-OM, and how environmental filtering can change archaeal communities relatively quickly in response to shifting terrestrial C sources [44]. Regardless, these data indicate that the microbial community biomass developed in the first few months of decomposition is sufficient to keep up degradation rates with $\mathrm{OM}$ increasing up to $25 \%$ concentration (Fig. $2 b$ ).

An important factor that shaped the methanogen community composition and $\mathrm{CH}_{4}$ concentrations was the host lake. We predicted that trophic status of each lake would be an important predictor of sediment $\mathrm{CH}_{4}$ concentrations, with more $\mathrm{C}$ mineralization in lakes containing higher nutrient loads, allowing them to be primed for increased 


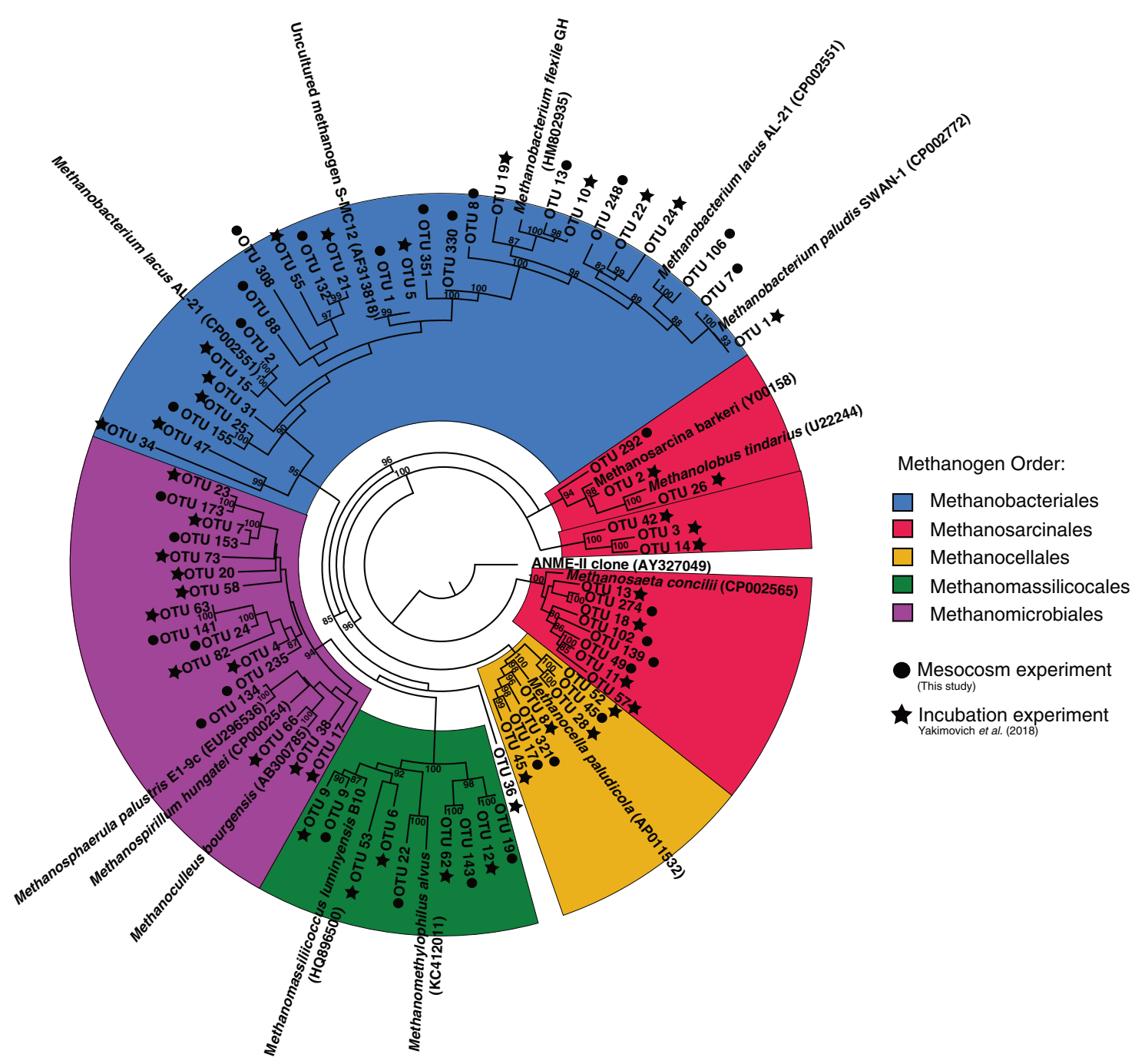

Fig. 5 Maximum likelihood phylogenetic tree with bootstrap values (1000 replicates; values $>\mathbf{8 0}$ are labeled on the nodes) of the methanogen OTUs from the present mesocosm study and the

rates of decomposition, and subsequently methanogenesis. However, we did not observe this outcome, as both the dystrophic and mesotrophic lakes had lower methane concentrations than the oligotrophic lake. Our analysis suggested this was a result of differing degrees of inhibition on methanogenesis by HMW-C between lakes as measured by mHIX (Fig. 3a). Previous work showed that greater solar irradiation of lake sediments resulted in increased mineralization rates by sediment microbes, due to easier-toutilize metabolites created via photooxidation [21]. However, in a dark lake the sediment microbes invested in costly enzymes to degrade HMW-C, and had lower mineralization rates (as in the dystrophic lake in this study). We see that pattern reflected in our results, where the highly irradiated sediments in the oligotrophic lake had increased methanogenesis (Figs. 2d, 3b) - that could not be explained by water temperatures, as there were only incubation experiment in Yakimovich et al. [15]. Note that the OTU numbers were assigned independently for each study, resulting in duplicate OTU numbers in this figure.

small differences between lakes (Fig. 3c). With similar light levels between the dys- and meso-trophic lakes, the differences in $\mathrm{CH}_{4}$ production was likely due to differences in available nutrients for bacteria to biosynthesize enzymes required for HMW-C degradation. The steeper slope in the lower-nutrient mesotrophic lake relative to that of the dystrophic lake further supports this interpretation (Fig. 3a). An alternative, but not mutually exclusive, explanation for differences in $\mathrm{CH}_{4}$ concentrations corresponding with varying light levels between lakes is inhibition of methanotrophs. Previous lab and field studies in the water column and sediments showed increasing inhibition of methanotrophic activity with increasing light intensity [45, 46]. As our measurements of $\mathrm{CH}_{4}$ concentrations here are of net production we cannot estimate the role of methanotrophs in this system, however no known anaerobic methane oxidizer taxa were detected in 

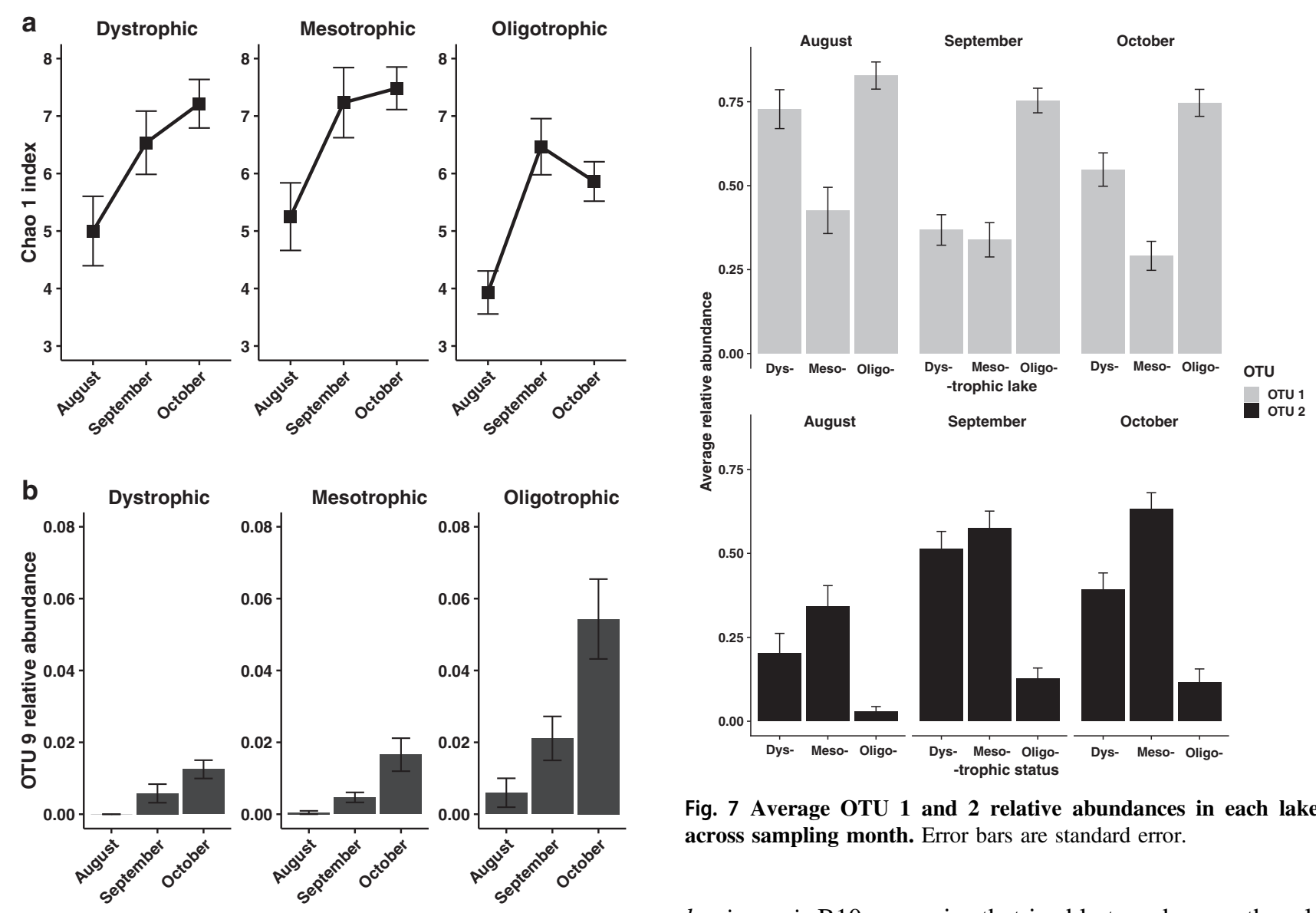

Fig. 7 Average OTU 1 and 2 relative abundances in each lake across sampling month. Error bars are standard error.

Fig. 6 Changes in species richness were similar across lakes over time. a Chao 1 species richness index and $\mathbf{b}$ relative abundance of OTU 9 over sampling month in each lake. Error bars are standard errors.

our sequencing data. In contrast to light, temperature surprisingly did not vary much between lakes (Fig. 3c).

We found that the mesocosms were colonized by the same taxa of methanogens found in lab incubations where natural lake sediments were used [15]; suggesting the sediments constructed for this study have the same metabolic capacity. In all lakes, there was a sharp increase in methanogen richness between August and September, suggesting that there was a large initial recruitment of new methanogens to the sediments, establishing a community. No single OTU seemed to be attributed to higher methane concentrations overall, but the presence of certain taxa seem to suggest specialization within the methanogen community. There were also slight differences in overall composition between each lake (Fig. 4). These differences were driven by both the presence and relative abundance of the Methanomassiliicoccales OTU 9, which was found to increase in abundance over time in the oligotrophic lake (Fig. 6b), and by the differences in patterns between OTUs 1 and 2 (Fig. 7). Our phylogenetic analysis (Fig. 5) indicates that OTU 9 is closely related to Methanomassiliicoccus

luminyensis B10, a species that is able to reduce methanol, with hydrogen as an electron source to perform methanogenesis [47]. Higher methanol concentrations could be a direct result of the more rapid decomposition of HMW-C owing to higher rates of photooxidation, which then resulted in larger populations of OTU 9 in the oligotrophic lake. The role of local conditions (i.e., within lake) as major drivers of methanogen community composition is in line with our previous work, where we found that the taxonomic and metabolic functions of the sediment microbial community responded differently to identical additions of t-OM in different lakes [21, 44].

\section{Conclusion}

Methanogens in shallow lake sediments contribute significant amounts of $\mathrm{CH}_{4}$ annually to the atmosphere, offsetting the current terrestrial C sink. Here, we investigated how methanogen communities were shaped by concentrations and ratios of different dominant terrestrial leaf litter added to lake sediments. Overall, the ratio of fresh deciduous-to-coniferous litter had no significant effect on methanogenesis, however the addition of any litter increased methanogenesis up to a threshold, beyond which inhibition occurred. 
Trophic status alone did not predict methane concentrations either, as photooxidation in the oligotrophic lake may have accelerated the decomposition of HMW-C, thereby providing more readily available metabolites for methanogens and their syntrophic partners. However, when light levels were similar between lakes, a dystrophic lake with higher nutrient levels had faster methanogenesis, likely because the syntrophic sediment bacteria increased catalytic capabilities. Therefore, lake trophic status and water clarity are important factors to consider when evaluating how land use changes around lakes will alter methane production and emissions in littoral zones.

Acknowledgements We would like to thank Cyndy Desjardins, Beth Smith, Toby Livesey, Ashley Simkins, and Charlotte Armitage for help with field sampling. We are also grateful to The Living with Lakes Centre at Laurentian University for logistical support and Conservation Sudbury for allowing us to carry out our experiment in Lake Laurentian. We also thank the NERC-NBAF Sheffield for help with amplicon sequencing.

Funding Funding came from a Natural Environment Research Council grant NE/L006561/1 and NBAF Grant NBAF968 to AJT.

\section{Compliance with ethical standards}

Conflict of interest The authors declare no conflicts of interest.

Publisher's note Springer Nature remains neutral with regard to jurisdictional claims in published maps and institutional affiliations.

\section{References}

1. Bastviken D, Tranvik LJ, Downing J, Crill JA, Enrich-prast MP. A. freshwater methane emissions offset the continental carbon sink. Science. 2011;331:50.

2. Myhre G, Shindell D, Breon F, Collins W, Fuglestvedt J, Huang J, et al. Anthropogenic and natural radiative forcing. In: Stocker TF, Qin D, Plattner G-K, Tignor M, Allen SK, Boschung J, et al., editors. Climate change 2013: the physicial science basis. Contribution of Working Group I to the Fifth Assesment Report of the Intergovernmenal Panel on Climate Change. 2013. Cambridge University Press, Cambridge.

3. Drake TW, Raymond PA, Spencer RGM. Terrestrial carbon inputs to inland waters: a current synthesis of estimates and uncertainty. Limnol Oceanogr Lett. 2018;3:132-42.

4. Bastviken D, Cole JJ, Pace ML, Van de Bogert MC. Fates of methane from different lake habitats: connecting whole-lake budgets and $\mathrm{CH}_{4}$ emissions. J Geophys Res. 2008;113:G02024.

5. Hofmann H, Federwisch L, Peeters F. Wave-induced release of methane: littoral zones as a source of methane in lakes. Limnol Oceanogr. 2010;55:1990-2000.

6. Scandella BP, Pillsbury L, Weber T, Ruppel C, Hemond HF, Juanes R. Ephemerality of discrete methane vents in lake sediments. Geophys Res Lett. 2016;43:4374-81.

7. West WE, Creamer KP, Jones SE, Wickland K, Hamdan LS. Productivity and depth regulate lake contributions to atmospheric methane. Limnol Oceanogr. 2016;61:S51-S61.
8. Hanlon RDG. Allochthonous plant litter as a source of organic material in an oligotrophic lake (Llyn Frongoch). Hydrobiologia. 1981;80:257-61.

9. Mcinerney MJ, Sieber JR, Gunsalus RP. Syntrophy in anaerobic global carbon cycles. Curr Opionion Biotechnol. 2009; 623-32.

10. Tanentzap AJ, Szkokan-Emilson EJ, Kielstra BW, Arts MT, Yan ND, Gunn JM. Forests fuel fish growth in freshwater deltas. Nat Commun. 2014;5:4077.

11. Cole JJ, Prairie YT, Caraco NF, McDowell WH, Tranvik LJ, Striegl RG, et al. Plumbing the global carbon cycle: integrating inland waters into the terrestrial carbon budget. Ecosystems. 2007;10:172-85.

12. Thebrath B, Rothfuss F, Whiticar MJ, Conrad R. Methane production in littoral sediment of Lake Constance. FEMS Microbiol Lett. 1993;102:279-89.

13. Foley JA, DeFries R, Asner GP, Barford C, Bonan G, Carpenter $\mathrm{SR}$, et al. Global consequences of land use. Science. 2005;309:570-4.

14. Millar CI, Stephenson NL, Stephens SL. Climate change and forests of the future: managing in the face of uncertainty. Ecol Appl. 2007;17:2145-51.

15. Yakimovich KM, Emilson EJS, Carson MA, Tanentzap AJ, Basiliko N, Mykytczuk NCS. Plant litter type dictates microbial communities responsible for greenhouse gas production in amended lake sediments. Front Microbiol. 2018;9:1-13.

16. Emilson EJS, Carson MA, Yakimovich KM, Osterholz H, Dittmar $\mathrm{T}$, Gunn JM, et al. Climate-driven shifts in sediment chemistry enhance methane production in northern lakes. Nat Commun. 2018;9:1-6.

17. Hansen AM, Kraus TEC, Pellerin BA, Fleck JA, Downing BD, Bergamaschi BA. Optical properties of dissolved organic matter (DOM): Effects of biological and photolytic degradation. Limnol Oceanogr. 2016;61:1015-32.

18. Osburn CL, Morris DP, Thorn KA, Moeller RE. Chemical and optical changes in freshwater dissolved organic matter exposed to solar radiation. Biogeochemistry. 2001;54:251-78.

19. Yap SD, Astals S, Lu Y, Peces M, Jensen PD, Batstone DJ, et al. Humic acid inhibition of hydrolysis and methanogenesis with different anaerobic inocula. Waste Manag. 2018;80:130-6.

20. Khadem AF, Azman S, Plugge CM, Zeeman G, van Lier JB, Stams AJM. Effect of humic acids on the activity of pure and mixed methanogenic cultures. Biomass- Bioenergy. 2017;99:21-30.

21. Fitch A, Orland C, Willer D, Emilson EJS, Tanentzap AJ. Feasting on terrestrial organic matter: Dining in a dark lake changes microbial decomposition. Glob Chang Biol. 2018;24:5110-22.

22. Williamson CE, Morris DP, Pace ML, Olson OG. Dissolved organic carbon and nutrients as regulators of lake ecosystems: resurrection of a more integrated paradigm. Limnol Oceanogr. 1999;44:795-803.

23. Tanentzap AJ, Szkokan-Emilson EJ, Desjardins CM, Orland C, Yakimovich K, Dirszowsky R, et al. Bridging between litterbags and whole-ecosystem experiments: a new approach for studying lake sediments. J Limnol. 2017;76:431-7.

24. Ohno T. Fluorescence inner-filtering correction for determining the humification index of dissolved organic matter. Environ Sci Technol. 2002;36:742-6.

25. Aberg J, Wallin MB. Evaluating a fast headspace method for measuring DIC and subsequent calculation of $\mathrm{pCO}(2)$ in freshwater systems. Inl Waters. 2014;4:157-66.

26. Miller DN, Bryant JE, Madsen EL, Ghiorse WC. Evaluation and optimization of DNA extraction and purification procedures for soil and sediment samples. Appl Environ Microbiol. 1999;65:4715-24. 
27. Angel R, Claus P, Conrad R. Methanogenic archaea are globally ubiquitous in aerated soils and become active under wet anoxic conditions. ISME J. 2011;6:847-62.

28. Masella AP, Bartram AK, Truszkowski JM, Brown DG, Neufeld JD. PANDAseq: PAired-eND Assembler for Illumina sequences. BMC Bioinforma. 2012;13:1-7.

29. Edgar RC. Search and clustering orders of magnitude faster than BLAST. Bioinformatics. 2010;26:2460-1.

30. Wang Q, Garrity GM, Tiedje JM, Cole JR. Naive Bayesian classifier for rapid assignment of rRNA sequences into the new bacterial taxonomy. Appl Environ Microbiol. 2007;73: 5261-7.

31. Yang S, Liebner S, Alawi M, Ebenhöh O, Wagner D. Taxonomic database and cut-off value for processing morA gene 454 pyrosequencing data by MOTHUR. J Microbiol Methods. 2014; 103:3-5.

32. Clark K, Karsch-Mizrachi I, Lipman DJ, Ostell J, Sayers EW. GenBank. Nucleic Acids Res. 2016;44:D67-D72.

33. Katoh K, Misawa K, Kuma K, Miyata T. MAFFT: a novel method for rapid multiple sequence alignment based on fast Fourier transform. Nucleic Acids Res. 2002;30:3059-66.

34. Kumar S, Stecher G, Tamura K. MEGA7: molecular evolutionary genetics analysis version 7.0 for bigger datasets. Mol Biol Evol. 2016;33:1870-4.

35. Trifinopoulos J, Nguyen L-T, von Haeseler A, Minh BQ. W-IQTREE: a fast online phylogenetic tool for maximum likelihood analysis. Nucleic Acids Res. 2016;44:232-5.

36. R Core Team. R: a language and environment for statistical computing. R Foundation for Statistical Computing. Vienna, Austria; 2016.
37. McMurdie PJ, Holmes S. phyloseq: an R package for reproducible interactive analysis and graphics of microbiome census data. PLoS ONE. 2013;8:1-11.

38. Pinheiro J, Bates D, DebRoy S, Sarkar D, R Core Team. nlme: linear and nonlinear mixed effects models. 2017.

39. Lenth R. emmeans: Estimated Marginal Means, aka Least-Squares Means. 2019.

40. Long JA. interactions: Comprehensive, user-friendly toolkit for probing interactions. 2019.

41. Oksanen J, Blanchet FG, Friendly M, Kindt R, Legendre P, McGlinn D, et al. Vegan: community ecology package. 2017.

42. De Caceres M, Legendre P. Associations between species and groups of sites: indices and statistical inference. Ecology. 2009;90:3566-74.

43. Vavrek MJ. Fossil: palaeoecological and palaeogeographical analysis tools. Palaeontol Electron. 2011;14:1-16.

44. Orland C, Yakimovich KM, Mykytczuk NCS, Basiliko N, Tanentzap AJ. Think global, act local: The small-scale environment mainly influences microbial community development and function in lake sediment. Limnol Oceanogr 2020;65:S88-S100.

45. Dumestre JF, Guézennec J, Galy-Lacaux C, Delmas R, Richard S, Labroue L. Influence of light intensity on methanotrophic bacterial activity in Petit Saut Reservoir, French Guiana. Appl Environ Microbiol. 1999;65:534-9.

46. Murase J, Sugimoto A. Inhibitory effect of light on methane oxidation in the pelagic water column of a mesotrophic lake (Lake Biwa, Japan). Limnol Oceanogr. 2005;50:1339-43.

47. Gorlas A, Robert C, Gimenez G, Drancourt M, Raoult D. Complete genome sequence of Methanomassiliicoccus luminyensis, the largest genome of a human-associated Archaea species. J Bacteriol. 2012;194:4745. 